\title{
Land Use Diversification and Intensification on Elk Winter Range in Greater Yellowstone: Framework and Agenda for Social- Ecological Research
}

\section{Authors: Julia Hobson Haggerty, Kathleen Epstein, Michael Stone, \& Paul C. Cross}

NOTICE: this is the author's version of a work that was accepted for publication in Rangeland Ecology \& Management. Changes resulting from the publishing process, such as peer review, editing, corrections, structural formatting, and other quality control mechanisms may not be reflected in this document. Changes may have been made to this work since it was submitted for publication. A definitive version was subsequently published in Rangeland Ecology \& Management, VOL\# 71, ISSUE\# 2, (March 2018)] DOI\#10.1016/j.rama.2017.11.002

Haggerty, Julia Hobson, Kathleen Epstein, Michael Stone, and Paul C. Cross. "Land Use Diversification and Intensification on Elk Winter Range in Greater Yellowstone: Framework and Agenda for Social-Ecological Research." Rangeland Ecology \& Management 71, no. 2 (March 2018): 171-174. DOI:10.1016/j.rama.2017.11.002. 


\title{
Research Note
}

\section{Land Use Diversification and Intensification on Elk Winter Range in Greater Yellowstone: Framework and Agenda for}

\section{Social-Ecological Research}

\author{
Julia Hobson Haggerty ${ }^{\mathrm{a}, *}$, Kathleen Epstein ${ }^{\mathrm{a}}$, Michael Stone ${ }^{\mathrm{a}}$, Paul C. Cross ${ }^{\mathrm{b}}$ \\ ${ }^{a}$ Resources \& Communities Research Group, Department of Earth Sciences, Montana State University, Bozeman, MT 59715, USA \\ b US Geological Survey, Northern Rocky Mountain Science Center, Bozeman, MT 59715, USA
}

\begin{abstract}
A B S T R A C T
Amenity migration describes the movement of peoples to rural landscapes and the transition toward tourism and recreation and away from production-oriented land uses (ranching, timber harvesting). The resulting mosaic of land uses and community structures has important consequences for wildlife and their management. This research note examines amenity-driven changes to social-ecological systems in the Greater Yellowstone Ecosystem, specifically in lower elevations that serve as winter habitat for elk. We present a research agenda informed by a preliminary and exploratory mixed-methods investigation: the creation of a "social-impact" index of land use change on elk winter range and a focus group with wildlife management experts. Our findings suggest that elk are encountering an increasingly diverse landscape with respect to land use, while new ownership patterns increase the complexity of social and community dynamics. These factors, in turn, contribute to increasing difficulty meeting wildlife management objectives. To deal with rising complexity across social and ecological landscapes of the Greater Yellowstone Ecosystem, future research will focus on property life cycle dynamics, as well as systems approaches.
\end{abstract}

\section{Introduction}

The 1990s ushered in a new period of land use in many highamenity rural areas with important conservation and biodiversity values. Alongside an expansion of new land uses (Sorice et al., 2014), new land use patterns (Gill et al., 2010), and rapid human inmigration (Hansen et al., 2002; Gude et al., 2006; Gosnell and Abrams, 2011), mixed conservation outcomes have accompanied this amenity transition: a well-resourced cohort of advocates for conservation encourage rest and revitalization of some lands and waterways (Gosnell et al., 2006), while increased development and population growth contribute to habitat loss and increased pressure on regional ecosystem services. The amenity transition has also precipitated change in key institutions of resource management, as planning boards, conservation districts, and watershed groups show growing diversity in values and goals of their membership (Robbins et al., 2012). No longer a new but rather a well-established dynamic, the amenity transition continues to generate new land uses and community changes with important social-ecological implications and the potential for larger destabilizing effects.

\section{Land Use Change in the Greater Yellowstone Ecosystem}

The Greater Yellowstone Ecosystem (GYE) is one of the world's last remaining intact large-scale ecosystems and provides critical habitat for numerous iconic wildlife species (Marston and Anderson, 1991). Many such animals including elk, deer, pronghorn, bighorn sheep, and bison migrate across geographies that link the protected core of the GYE-Yellowstone and Grand Teton National Parks-with public and private lands where human activities have a decisive imprint. Over the past 40 years, the region has experienced immense growth; the human population from 1970 to 1999 increased by 58\% (Gude et al., 2006). As a result of the region's multidecade transition away from the dominance of primary industries (farming, timber, mining) into an economy reliant on services, amenity consumption, and nonlabor income, the GYE has witnessed a rapid expansion of amenity ranch ownership, as well as exurban, suburban, and urban development (Hansel et al., 2002).

These changes have important implications for how elk move on and use private lands in the GYE. Private land typically provides low- 
elevation winter habitat and important migratory corridors to (Burcham et al., 1999) and access to high-protein forage (such as cultivated hay and alfalfa). Elk also may use private land and/or housing structures as safe harbors from hunters and predators (Proffitt et al., 2011). Alongside changes to the physical landscape that shift the distribution of elk attractants and deterrents, new landowners may differ in their tolerance for the presence of elk on their property (largely expressed through different approaches to elk hunting). This heterogeneity can amplify conflict among stakeholder groups (Hegel et al., 2009). For example, elk in this region present a disease risk for the transmission of brucellosis to cattle (Cross et al., 2010), which can result in the depopulation of cattle herds or extended quarantines. The mixture of amenity and livestock owners and their diverse attitudes toward wildlife (Gosnell et al., 2006) can limit the options for wildlife managers.

This note addresses transitions in the ownership and management of private lands that serve as critical seasonal habitat for elk in the GYE. Previous research has examined drivers of regional development and land use change (Gude et al., 2006) and land tenure transition (Haggerty and Travis, 2006); however, the continued pressure of amenity migration on current wildlife management objectives (Cross et al., 2010) necessitates further investigation. This study enlists an exploratory, mixed methods approach as means to generate hypotheses and assess future research needs. The approach includes spatial analysis to assess recent land use trends affecting elk winter range in the Montana portion of the GYE. We also solicited expert opinion to characterize the range of ways that private land owners of elk winter range interact with elk and wildlife management. Here, we apply the results to updating and expanding the conceptual framework for understanding the interactions between the amenity transition, ecology, and wildlife management in the GYE (DeFries et al., 2007; Bennett and McGinnis, 2008).

\section{Methods}

We applied a mixed methods strategy to track ecological and social change on elk winter range in the Montana portion of the GYE. We spatialized descriptive statistics on the rate and volume of land use change across elk winter range in the study area. We then collected qualitative data from local wildlife biologists to capture their expert knowledge about the diversity of landowner approaches to land use. Elk winter ranges (EWRs) are spatial areas designated by state wildlife biologists using available location and habitat data; they represent the probable location of elk herds during winter (Foundation, 2014). Elk winter range units serve as the basis for analysis because they describe geographies with high likelihood of elk-human encounters. Within the Montana portion of the GYE there are 28 unique EWRs consisting of a total of 3.3 million acres of land with $51 \%$ (or 1.6 million acres) in private holdings.

\section{Quantifying Land Use Change}

We quantified change in two land use characteristics relevant to elk movements and density (Hegel et al., 2009; Proffitt et al., 2011): the amount of new residential structures (and associated parcel subdivision) and the amount of center pivot-irrigated alfalfa. (For a detailed description of the data processing and computational approaches, see
Appendix SI, available online at https://doi.org/10.1016/j.rama.2017. 11.002.) Briefly, we derived residential housing patterns from Gude's, 2017 dataset (after their 2006 dataset), which associates residential structures to the quarter-section geography on an annual basis. A comparison of two versions of the Montana cadastral database (2007 and 2016) provided changes in parcel patterns (MSL, 2007, 2016). The alfalfa data were derived from the 2007 and 2015 US Department of Agriculture's Cropland Data Layer (USDA, 2007, 2015). Using global information system analysis, we ranked each variable by relative and absolute change at the EWR level, sorted the distribution into thirds (tertiles), and aggregated all three variables into a "social-impact" index to identify winter ranges undergoing high, medium, and low levels of combined land use change.

\section{Administrative Challenges for Wildlife Management}

We used a map-assisted focus group to understand the social aspects of the changing private landscape and generate hypotheses for future work. Partners at the Montana Department of Fish, Wildlife and Parks assisted in selecting recognized experts $(n=7)$ in wildlife management who work at the local, regional, and state scales as participants. Experts were chosen on the basis of their official capacity in administering wildlife management policies and programs. Alongside maps of their associated management jurisdictions, we asked participants to consider how the quality of the "fit" between private land management and wildlife management priorities varies across private landscapes in the Montana GYE and to discuss the range of perceived motivations behind practices affecting elk winter range habitat and elk distribution and density. Maps were used to generate discussion; detailed notes were taken during the conversation and coded for emergent themes.

\section{Results}

\section{Physical Land Use Change}

Land use in the GYE is undergoing various levels of change including substantial increases across all three land use variables (Table 1 ). The number of new residential structures tracks closely with the region's explosive population growth, which was 17\% from 2005 to 2015 for the six counties (American Community Survey Office, 2016).

Elk winter ranges associated with known amenity development such as EWR 108 (Madison Valley), 95 and 87 (Paradise Valley), and 122 (Big Sky Resort) show high rates of land use change across all three land use variables (Fig. 1).

\section{Land Use and Wildlife Management Conflicts}

Wildlife manager focus group participants identify a complex pattern of land use and elk interactions on private elk winter range. Participants assigned the greatest potential for conflict between landowner and wildlife management objectives to "border areas" with opposing land management practices (e.g., a fence line and meadow managed by individuals with high tolerance for elk next to properties where elk are actively hazed).

Table 1

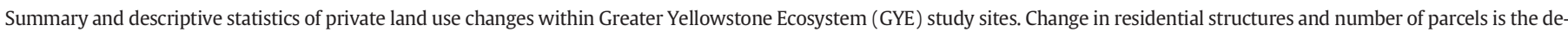
cadal change (from 2004 to 2013 and 2007 to 2016, respectively). Given data availability, change in acres of alfalfa was computed over a 9-yr interval (2007 - 2015).

\begin{tabular}{|c|c|c|c|}
\hline & & Volume change & Percent change \\
\hline \multirow[t]{3}{*}{ Across Montana GYE counties } & Acres of irrigated alfalfa & +51000 & $288 \%$ \\
\hline & Number of residential structures & +3371 & $18 \%$ \\
\hline & Number of parcels $<320$ acres & +2355 & $5.2 \%$ \\
\hline \multirow[t]{3}{*}{ Within elk winter ranges } & Acres of irrigated alfalfa & +22368 & $351 \%$ \\
\hline & Number of residential structures & +1374 & $16 \%$ \\
\hline & Number of parcels $<320$ acres & +1524 & $8.6 \%$ \\
\hline
\end{tabular}




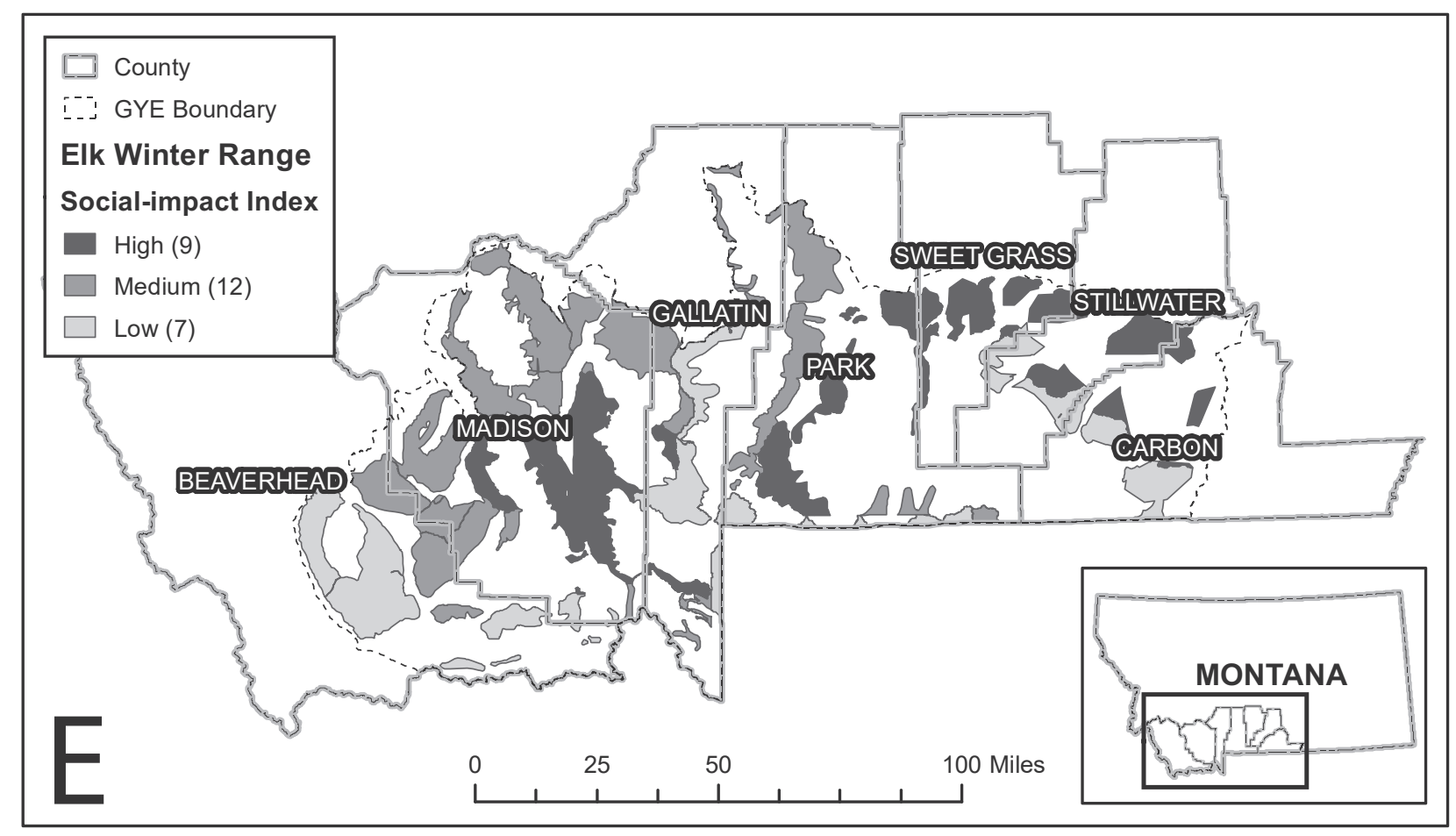

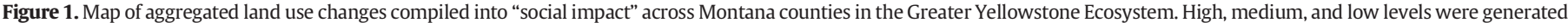
using tertiles of percent increases over years of analysis. Data source in Appendix 1.

Participants described a range of personal attitudes and values they perceived as key influences on private land management and the nature of conflict among neighbors and between landowner and wildlife management goals. We distilled these into three domains:

1. neighboring: the value placed on harmonious personal relationships and communication with their immediate neighbors. Examples include consulting community members directly on land management issues rather than soliciting intermediary services, such as personal lawyers;

2. heritage: the degree of personal investment in local conventions, such as public hunting access; and

3. habitat: the extent to which landowners enhance properties for wildlife. In the case of elk, this can include harboring or hazing elk at various times of the year.

Not mutually exclusive and occurring in novel combinations, landowner positions with respect to neighboring, heritage, and habitat are dynamic over time.

\section{Discussion}

Agricultural intensification, increased residential development, and ownership fragmentation are important indicators of shifting human development and land use patterns (Hansen et al., 2002; Gosnell et al., 2006; Haggerty and Travis, 2006). The pace of new residential development was nearly as fast on elk winter range (a decadal increase of $16 \%$ in the number of residential structures) as on private land generally (a decadal increase of $18 \%$ in the number of residential structures). Furthermore, the rate of new parcel development and thus potential subdivision on private land in winter ranges outpaced the growth rate on private lands countywide, suggesting that elk winter range has particular vulnerability to development. Most notably, our results show this increase in residential development occurs alongside-as opposed to instead of-agricultural intensification. Consider EWRs 122 and 108 that rank among the fastest changing winter range units in this study. Composed of large proportions of private land ( $\geq 50 \%)$, these winter ranges are located in rural counties far from population centers and in areas with high concentration of elk winter range use (MT FWP, 2004). In these two EWRs, both home construction and alfalfa production increased by substantial volumes, indicating a pattern of mixed intensification and diversification of land use. Thus, in these types of EWRs, elk encounter both new houses with their associated attractants and deterrents and also an intensifying agricultural landscape with its attractant (high-quality forage). At the same time, elk share the landscape with a growing constituency of non-ranching land owners and residents. And while the expansion of residential properties conceivably increases the area of land hospitable to elk (through the exclusion of hunting and tolerance or solicitation of their presence), in these places elk also encounter growth in nuisances such as fences, automobile traffic, and pets. At a minimum, these data suggest elk are encountering an increasingly diverse landscape in terms of land uses.

Alongside shifting land use patterns driving elk onto private lands and out of administrative control (Haggerty and Travis, 2006), our focus group results suggest that social landscapes across the study sites are increasingly diverse. Other research has also noted the difficulties of integrating amenity owners or nontraditional owners into production or traditional owner communities (Yung and Belsky, 2007) and the importance of improving landowner-hunter relations for wildlife management agendas (Campbell and Mackay, 2003). Managing populations based on wildlife stakeholder acceptance capacities is frequently practiced to reduce complexity and community conflict (Schusler et al., 2000). Our focus group results suggest that in regions with ownership change and turnover, the rural landowner cohort has increasingly diverse values, perspectives, and management priorities. We see the emerging domains of interest-neighborliness, heritage, and habitat-not as a method of categorization but rather as axes of those social variables closely connected to and sharing feedback with 
material ecological change. Taking these domains in combination with our social-impact index, we can begin to prioritize areas for future social-ecological research.

\section{Implications}

In this research note we presented a relatively simple way to track land use change and explored how land use changes are linked with social transitions and wildlife management conflicts to motivate future research agendas. Our results suggest that the social-ecological landscapes of the Greater Yellowstone are becoming increasingly diverse, through intensification of historical uses (ranching operations, alfalfa production) and multiuse populations (amenity driven subdivision and residential development), and complex, through the integration of new landowners and their associated values, perspectives, and management priorities. As these various elements of the social and ecological landscape are intrinsically linked, our exploratory and hypothesisgenerating work underscores the need to examine emerging amenity transitions in priority conservation regions through a social-ecological systems framework. Thus, driven from a systems perspective, we identify the following research tasks.

First, because shifting patterns of land tenure impact a suite of social and ecological processes from changes in hunting access to forage attractants, the GYE and other critical conservation regions need reliable ways to track land ownership change. From the perspective of wildlife management, adequately quantifying turnover and qualifying the characteristics of new owners will benefit planners interested in preserving wildlife corridors and equip wildlife managers with the demographic information need to strategize priorities and improve collaborations with private landowners.

As a complementary strategy, future research should prioritize the identification of drivers of change in landowner approaches to land management over time. To date, human dimensions scholarship in the GYE have been dominated by the discrete categorization of landowner types (Gosnell et al., 2006) and stakeholder typologies through surveys (Metcalf et al., 2015). This work is beneficial for characterizing differences within the landowner cohort but offers a static picture that belies the highly dynamic nature of landowner experience. In addition, our focus group results suggest that landowners may defy standard typologies. In response, we see that the decades-long amenity transition in the GYE offers the unique opportunity to examine how landowners learn from, adapt with, and integrate into their local social and ecological communities in both short- and long-duration cycles. Such an approach can yield new understanding of the role of social networks, personal experience, and the agency of nature in land use decision-making in the GYE.

A coupled social-ecological approach that recognizes the amenity transition in the GYE as a complex system has the potential to reveal and describe critical feedback loops between human and biophysical systems. With these feedbacks clarified, we can begin to address questions about threshold dynamics emerging in priority conservation regions undergoing amenity transitions.

Supplementary data to this article can be found online at https://doi. org/10.1016/j.rama.2017.11.002.

\section{Acknowledgments}

The authors acknowledge the cooperation of Montana Fish Wildlife and Parks. Special thanks to Patty Gude, Angela Brennan, and Quentin Kujala.

\section{References}

American Community Survey Office, 2016. American Community Survey. US Dept of Commerce, Washington, DC, USA.

Bennett, D., McGinnis, D., 2008. Coupled and complex: human-environment interaction in the Greater Yellowstone Ecosystem, USA. Geoforum 39 (2), 833-845.

Burcham, M., Edge, W.D., Marcum, C.L., 1999. Elk, use of private land refuges. Wildlife Society Bulletin 27, 833-839.

Campbell, J.M., Mackay, K.J., 2003. Attitudinal and normative influences on support for hunting as a wildlife management strategy. Human Dimensions of Wildlife 8, 181-197.

Cross, P.C., Cole, E.K., Dobson, A.P., Edwards, W.H., Hamlin, K.L., Luikart, G., Middleton, A.D. Scurlock, B.M., White, P.J., 2010. Probable causes of increasing brucellosis in freeranging elk of the Greater Yellowstone Ecosystem. Ecological Applications 20, 278-288.

DeFries, R., Hansen, A., Turner, B.L., Reid, R., Liu, J., 2007. Land use change around protected areas: management to balance human needs and ecological function. Ecological Applications 17 (4), 1031-1038.

Gill, N., Klepeis, P., Chisholm, L., 2010. Stewardship among lifestyle oriented rural landowners. Journal of Environmental Planning and Management 53, 317-334.

Gosnell, H., Abrams, J., 2011. Amenity migration: diverse conceptualizations of drivers, socioeconomic dimensions, and emerging challenges. GeoJournal 76, 303-322. https://doi.org/10.1007/s10708-009-9295-4.

Gosnell, H., Haggerty, J.H., Travis, W., 2006. Ranchland ownership change in the greate yellowstone ecosystem, 1990-2001: implications for conservation. Society \& Natural Resources 19, 743-758.

Gude, P.H., 2017. Residential Housing Dataset, updated and maintained by Headwaters Economics.

Gude, P.H., Hansen, A.J., Rasker, R., Maxwell, B., 2006. Rates and drivers of rural residential development in the Greater Yellowstone. Landscape and Urban Planning 77, 131-151.

Haggerty, J.H., Travis, W.R., 2006. Out of administrative control: absentee owners, resident elk and the shifting nature of wildlife management in southwestern Montana. Geoforum 37, 816-830

Hansen, A.J., Rasker, R., Maxwell, B., Rotella, J.J., Johnson, J.D., Parmenter, A.W., Langner, U., Cohen, W.B., Lawrence, R.L., Kraska, M.P.V., 2002. Ecological causes and consequences of demographic change in the new West. BioScience 52 (2), 151-162. https://doi.org/ 10.1641/0006-3568(2002)052[0151:ECACOD]2.0.CO;2.

Hegel, T.M., Gates, C.C., Eslinger, D., 2009. The geography of conflict between elk and agricultural values in the Cypress Hills, Canada. Journal of Environmental Management 90, 222-235.

Marston, R.A., Anderson, J.E., 1991. Watersheds and vegetation of the Greater Yellowstone Ecosystem. Conservation Biology 5, 338-346.

Metcalf, E.C., Graefe, A.R., Trauntvein, N.E., Burns, R.C., 2015. Understanding hunting constraints and negotiation strategies: a typology of female hunters. Human Dimensions of Wildlife 20, 30-46.

Montana Department of Fish, Wildlife, and Parks (MT FWP), 2004. Montana Statewide Elk Management Plan.

Montana State Library (MSL), 2007. Cadastral, Montana Spatial Data Infrastructure.

Montana State Library (MSL), 2016. Cadastral, Montana Spatial Data Infrastructure.

Proffitt, K.M., Gude, J.A., Hamlin, K.L., Garrott, R.A., Cunningham, J.A., Grigg, J.L., 2011. Elk distribution and spatial overlap with livestock during the brucellosis transmission risk period. Journal of Applied Ecology 48, 471-478.

Robbins, P., Martin, S., Gilbertz, S., 2012. Developing the commons: the contradictions of growth in exurban Montana. The Professional Geographer 64, 317-331.

Rocky Mountain Elk Foundation, 2014. M.A.P. Elk Habitat Project.

Schusler, T.M., Chase, L.C., Decker, D.J., 2000. Community-based comanagement: sharing responsibility when tolerance for wildlife is exceeded. Human Dimensions of Wildlife 5, 34-49.

Sorice, M.G., Kreuter, U.P., Wilcox, B.P., Fox, W.E., 2014. Changing landowners, changing ecosystem? Land-ownership motivations as drivers of land management practices. Journal of Environmental Management 133, 144-152.

USDA, 2007. National Agricultural Statistics Service, Published crop-specific data layer. USDA-NASS, Washington, DC, USA.

USDA, 2015. National Agricultural Statistics Service, Published crop-specific data layer USDA-NASS, Washington, DC, USA.

Yung, L., Belsky, J.M., 2007. Private property rights and community goods: negotiating landowner cooperation amid changing ownership on the Rocky Mountain front. Society \& Natural Resources 20, 689-703. 